\title{
POLYSTYRENE EMBEDDED SILVER NANOPARTICLES AS POTENTIAL ZINC HEAVY METALS REMOVAL IN WASTEWATER REMEDIATION APPLICATION
}

\section{MOHD ARIF AGAM ${ }^{1 *}$, MAYTHAM QABEL HAMZAH ${ }^{2}$, BAGNER DECRUZZ JUILIS ${ }^{3}$, SITI ASHIKIN HASAN $^{4} \&$ JIBRIN ALHAJI YABAGI ${ }^{5}$}

${ }^{1}$ Associate Profesor, Department of Physics and Chemistry, University Tun Hussein Onn Malaysia, 84600 Pagoh, Muar, Johor, Malaysia

${ }^{2}$ PhD Student, Department of Physics and Chemistry, Faculty of Applied Sciences and Technology, UTHM University,

A Teacher in Directorate of Education Al-Muthanna, Ministry of Education, Republic of Iraq

${ }^{3}$ Degree Student, Department of Physics and Chemistry, Faculty of Applied Sciences and Technology, UTHM University

${ }^{4}$ MSc Student, Department of physics and chemistry, Faculty of applied sciences and Technology, UTHM University

${ }^{5}$ Lecturer, Department of Physics, Ibrahim Badamasi Babangida University, Lapai, Niger State, Nigeria

\begin{abstract}
A heavy metal such as Plumbum (II), Copper (II), Zinc (II), and Cadmium (II) is found in contaminated water and needs to be treated to reduce the well being danger to customers either human, verdure or fauna. As of late, polymermetal nanocomposites found to be potential as a heavy metal safeguard. In this research, report on the concentrate on synthesizing polystyrene entrenched (doped) with silver NPs (polystyrene-silver NPs) as faint-cost metal absorber material which ispossible to remove zink heavy metals from contaminated water is highlighted. The silver NPs in the range of $\sim 130 \mathrm{~nm}$ were bio-synthesized by Murayakoenigi leaves extract and the polystyrene is synthesised through nanoprecipitation method. The manufactured wastewater was prepared in the centralization of 10, 20 and $50 \mathrm{mg} / \mathrm{l}$ as models for lower to higher contaminated wastewater conditions. (FTIR) Fourier Transform Infrared spectrum, which is used to find out the chemical bonding of polystyrene-silver NCs and (AFM) atomic force microscopy is used to determine the topology of the surface and particle distribution. $U V$-Vis spectroscopy is used to analyze the rate of polystyrene-silver NCs absorbance and the concentration of zink in synthetic waste water. The polystyrene-silver NCs ability to remove zink heavy metals was contemplated using two main manipulate parameters, $\mathrm{pH}$ value and contact time. The removal of more than $70 \%$ of zink heavy metals by polystyrene-silver NPs from synthetic wastewater are within 30 minutes, in both controlled parameters. The ideal zink retention by polystyrene-silver NCs for the two proportions of 1:3 and 1:5 of polystyrene-silver NCs was at $91 \%$ at ideal state of $\mathrm{pH} 5$ and 50 minutes of contact times. This report shows polystyrenesilver NCs as a potential nano technology base heavy metal safeguard for the application and activity of wastewater development.
\end{abstract}

KEYWORDS: Metal Nanoparticles, Polystyrene, Silver Nanoparticles, Heavy Metals \& Water Remediation

Received: Jan 30, 2020; Accepted: Feb 19, 2020; Published: Apr 30, 2020; Paper Id.: IJMPERDJUN202020

\section{INTRODUCTION}

Since the major concern about the amount of made-up wastewater produced has been mounting lately, various heavy metals will be released as by-product industry, thus, contaminating the water which primarily one of the main resources of living things [1]. Heavy metals such as Zinc (Zn) particularly, is arguably obvious that one of the famous heavy metals that subsist in wastewater due to harmful main problems to people's health like anemia, diarrhoea, nausea and stomach cramps [2-4]. This has resulted in numerous technology or methods innovation to 
strip heavy metals in waste water treatment applications for example, filtration, absorption and advanced oxidation process [3-7]. Nanotechnology is said as the new technological breakthrough, as it influences to vast scientific fields that focus on atomic and molecular precision [8,9]. Nanotechnology offered a new approach in fabricating materials [10,11] and products [12-15], which innovate advancement in semiconductor device fabrication[16], drug delivery [16,17], microwave absorption [18-21], membrane fuel cell [22,23] or even high durability and strength of materials.

Nanotechnology deals at nano-size dimensions or nanoparticles where a large surface area ratio compared to its volume create strong binding sites (larger surface area to interact with other particles) [24,25]. Thus, the larger number of surface atoms creates a higher absorption rate especially for heavy metals absorption, which is suitable for heavy metals removal of waste water. Polymer (polystyrene (PS)) embedded through metal nanocomposites (Popystyrene-MNCs) which has features of both NPs and polystyrene would be the adsorbent to that heavy sensible metals because of its unprecedented surface district to each volume extent, exquisite mechanical highlights and agreeable fundamental in their polymer lattice [26]. These features certainly provide better performance to the heavy metals removal from the wastewater, knowing a promising and potential class of absorbent materials [27-29]. The overall objective in this research focuses on the synthesis of (polystyrene) embedded (silver) nanoparticles (polystyrene-silver NCs PS-Ag NCs)), characterization and absorption analysis. In this paper, we successfully showed that the absorption of polystyrene-silver NCs gave outstanding removal efficiencies of zink heavy metals. The main manipulate parameters are $\mathrm{pH}$ values that absorb zink metal ions and contact time in investigating zink heavy metal absorption.

\section{METHODOLOGY}

Polystyrene nanoparticles of sizes range were successfully synthesized by nano precipitation [30] method while silver nano particles of $\sim 130 \mathrm{~nm}$ range were synthesized via bio synthesis leaf extraction of Murayakoenigi that act as reducing agents [31]. The arrangement of polystyrene installed with silver nanocomposites was effectively arranged at two proportions of 1 polystyrene: 3 silver and 1 polystyrene: 5 silver. The sample arrangement planning begins by putting $2.5 \mathrm{ml}$ of polystyrene and $7.5 \mathrm{ml}$ (silver NPs) were seen utilizing ultrasonic cleaning machine with a length for 10 minutes and for 1 hour separately, Vortex Mixer, as a total solution of polystyrene-silver NCs of $10 \mathrm{ml}$. These solutions were coated on the silicon substrate via the dropping method and left evaporated at room temperature for 24 hours for AFM: surface morphology, FTIR: chemical bonding analysis and UV-Vis spectroscopy: absorption analysis.

Zink synthetic waste water was prepared via the conventional method. Stock solution prepared by adding $\mathrm{ZnSO}_{4} \cdot 7 \mathrm{H}_{2} \mathrm{O}$ into the distilled water of $1000 \mathrm{ml}$ volumetric flask and shacked at the steady motion to dissolve the zink metal ions [32]. The concentration of $10 \mathrm{mg} / \mathrm{l}, 20 \mathrm{mg} / \mathrm{l}$, and $50 \mathrm{mg} / \mathrm{l}$ was prepared from the $1000 \mathrm{mg} / \mathrm{l}$ stock solution preparation. The batch mode of absorption analysis utilizing orbital shaker is fixed at room temperature at $150 \mathrm{rpm}$ [3334]. Various $\mathrm{pH}$ of 1,3,4,7 and 9 are controlled by add-in few drops of HCL $1.0 \mathrm{M}$ for acid and $\mathrm{NaOH} 1.0 \mathrm{M}$ for alkali respectively into the prepared 10, 20 and $50 \mathrm{mg} / \mathrm{l}$ zink solution. In investigating the absorption efficiency, the contact time analysis was investigated, starting from 0 minutes, with 10 minutes' interval duration until the maximum of 70 minutes. The mix of polystyrene-silver NCs and zink heavy metal after each process of contact time was filtered with Whatman filter $0.45 \mu \mathrm{m}$ and later $\mathrm{PH}$ of the mixture was analyzed of its zink content corresponding to contact time. 


\section{RESULTS AND DISCUSSIONS}

\subsection{Polystyrene Embedded with Silver Nanocomposites}

Figure 1 shows the AFM pictures of polystyrene-silver NCs for the two proportions of 1:3 and 1:5. The clear and circular formed part was contemplated as polystyrene (PS) while a couple of little round pinnacles was demonstrated as silver nanoparticles, which inserted in the polystyrene NPs.

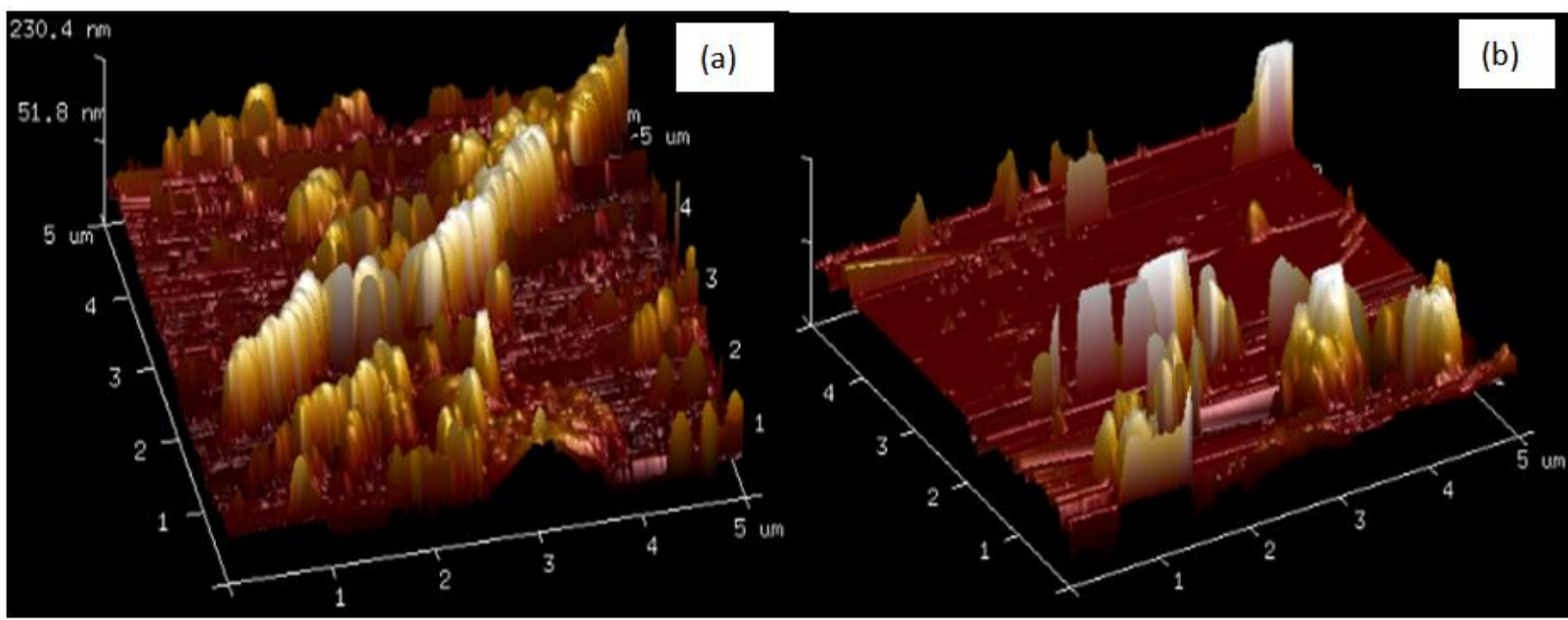

Figure 1: AFM of (a) 1:3 Ratios of Polystyrene-Silver NCs and (b) 1:5 Ratios of Polystyrene-Silver NCs.

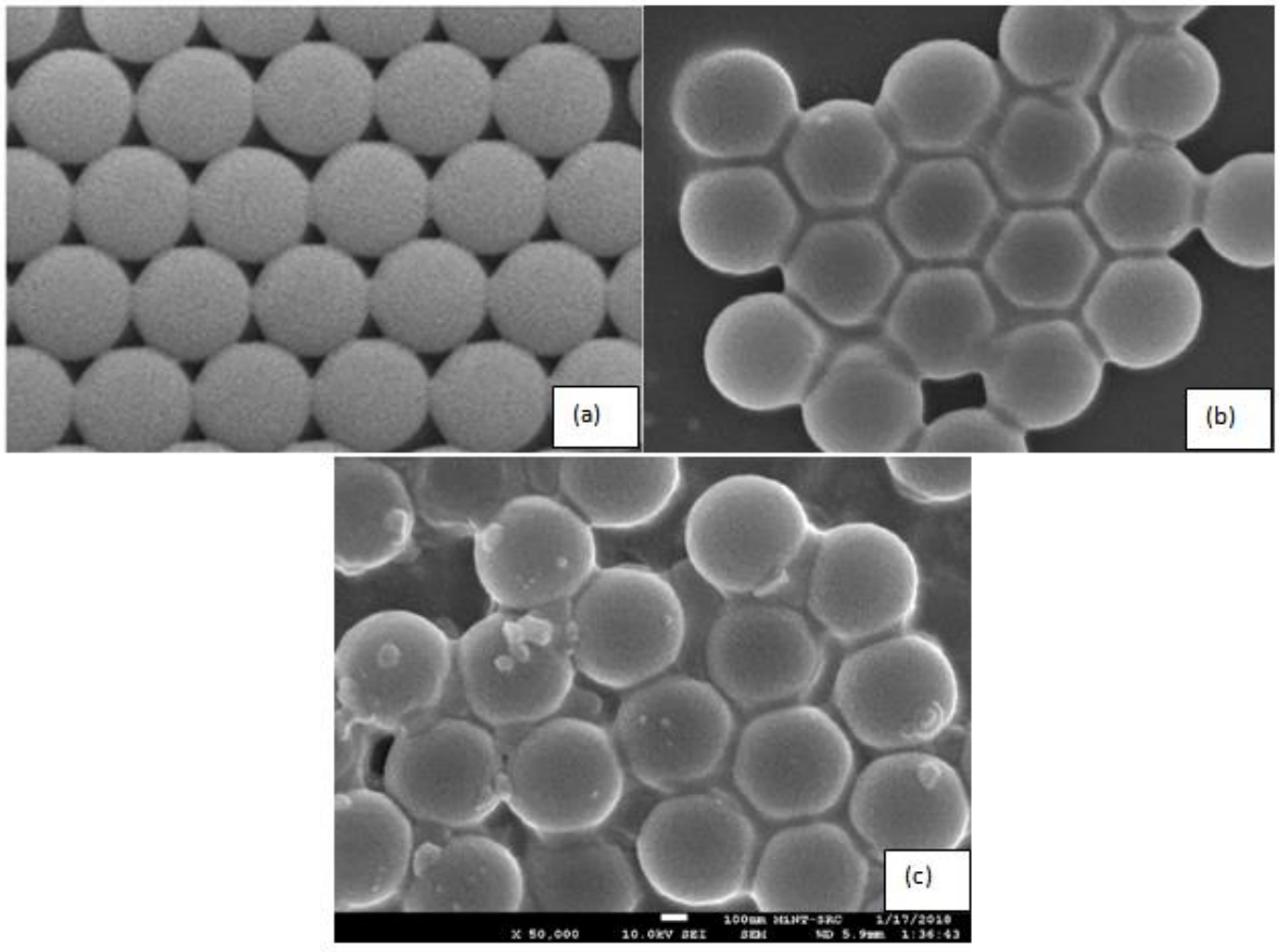

Figure 2: SEM Images of (a) Bare Polystyrene (b) 1:3 of Polystyrene: Silver NCs and (c) 1:5 of polystyrene: Silver NCs.

In Figure 2 (a), the bare polystyrene nanospheres can be seen clearly, but not in Figure 2 (b) and (c) as the Silver nano particles could have covered more to the polystyrene surfaces. A higher concentration of Silver will let Silver 
nanoparticles to agglomerate that lead to bulky shape on polystyrene surfaces. The normal distance across particles for 1:5 and 1:3 polystyrene installed silver NCs are around $362 \mathrm{~nm}$ and $256 \mathrm{~nm}$ individually. The distribution of silver nanoparticles is not investigated, nevertheless as reported by Raid the silver nanoparticles are small enough at first to fill the polystyrene pores to create a uniform and homogenous distribution of silver nanoparticles in the polystyrene matrices, thus created polystyrene-silver NCs [35, 33]. Nevertheless, the excess Silver nanoparticles on the surface will agglomerate, creating bulky images of Silver particles on polystyrene nanospheres surfaces. Due to the presence of binding spots of the silver NPs, the fascination was strong to its neighboring particles. The strong binding can be seen in Figure 2 (b) as polystyrene is found to be intact with each other, while Silver nanoparticles are seen to fill the voids between polystyrene nanospheres. The head state of silver nanoparticles barely was watched because it was doped into the polystyrene albeit some head was found in specific regions on account of the silver nanoparticles are limited in the outside of polystyrene. The micro-graph of 1:5 polystyrene implanted silver nano composites was spotted with sharp, calling attention to the tallness of particles in light of the estimation cases. Due to the gripping power which is high between the outside of the example and AFM summits, the thickness of the example surface adjusts AFM tips for performing halfway gathering the surface topology favored picture.
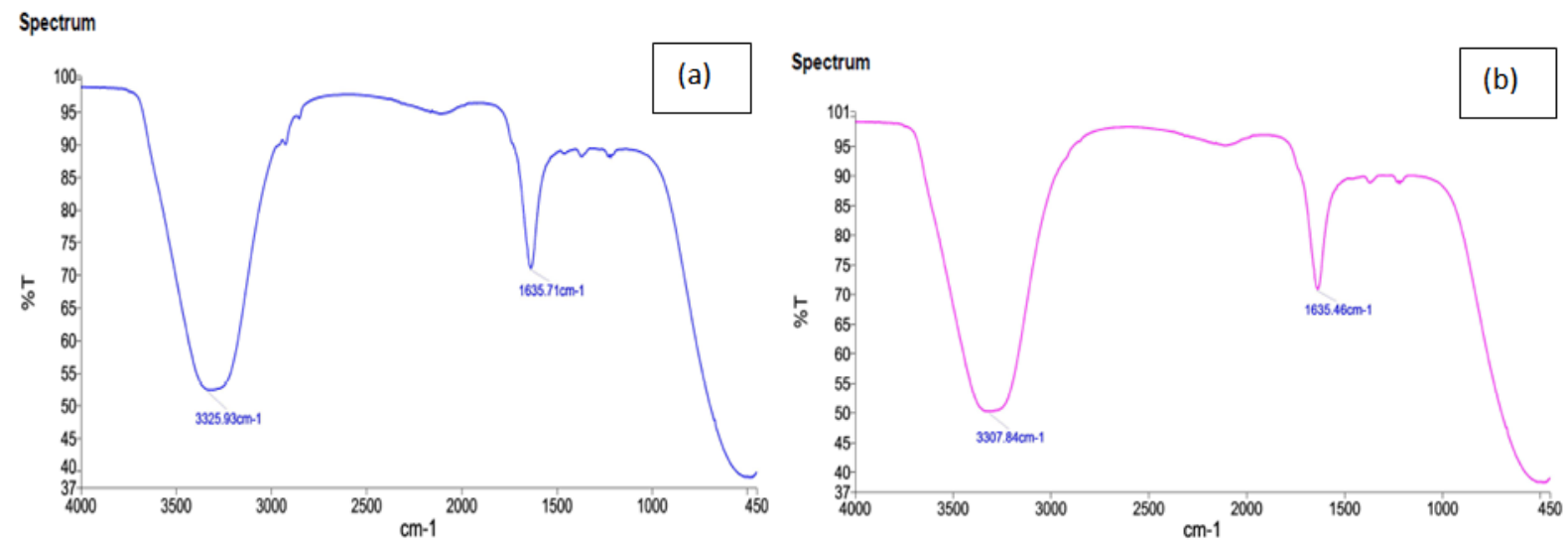

Figure 3: FTIR Spectrum for (a) 1:3 of Polystyrene: Silver NCs and (b) 1:5 of Polystyrene: Silver NCs.

FTIR was used to investigate the chemical properties of both ratios polystyrene-silver NCs of 1:3 and 1:5. The control doctrinaire of polystyrene to the synthesis plainly of polystyrene-silver NCs can be viewed in Figure 3, where several slight changes that happened in the FTIR polystyrene-silver NCs spectrum. The turnout of a wide peak was spotted at $3325.93 \mathrm{~cm}^{-1}$ and $3307.84 \mathrm{~cm}^{-1}$ for ratio $1: 5$ and 1:3 of polystyrene-silver NCs individually.

These two groups show up among the molecular hydrogen-reinforced of $\mathrm{O}-\mathrm{H}$ expanding vibrations. Pinnacle band at $1635.46 \mathrm{~cm}^{-1}$ and $1635.71 \mathrm{~cm}^{-1}$ at Figures 2 (a) and 2 (b) were likewise indicated separately, which proposed, the nearness of aliphatic $\mathrm{C}-\mathrm{H}$ mutilation vibrations and carbonyl stretch, recognized as the amide gathering. These two previously mentioned spectra toted the qualities of silver NPs, where the framing of silver NPs through Murayakoenigii extraction created was built up in the network of polystyrene-silver NCs. The sorts of polystyrene have shown up at the very little pinnacle of $1217.43 \mathrm{~cm}^{-1}$ and. $1386.02 \mathrm{~cm}^{-1}$ seen in Figure 3 a) and $1229.71 \mathrm{~cm}^{-1}, 1364.44 \mathrm{~cm}^{-1}$ in Figure 3 (b), which coordinated to distortion of aromatic $\mathrm{C}-\mathrm{H}$ bowing. This guide demonstrated that both a way from silver NPs have altered the vast majority of the synthetic holding that happens in polystyrene-silver NCs, yet at the same time, the polystyrene-kind substance holding trademark is as yet ready to show off its presence. 


\subsection{Absorption Analysis}

The retention test was led to check the activity of pH sums and contact arrange. Figure 4 (an) and (b) show pH activity on zink (heavy metals expulsion efficiencies) using 1:5 and 1:3 of polystyrene-silver NCs. The outcomes educated that the extent expulsion efficiencies to zink heavy metals was superfast from down $\mathrm{pH}$ to up at $\mathrm{pH} 5$, at that point declined mutually with the raise of the $\mathrm{pH}$ esteems. The pattern of the illustrative diagram was utilized in both 1:5 and 1:3 of polystyrene-silver NCs. At 1:3 of polystyrene-silver NCs, zink heavy metals were viably evacuated at $\mathrm{pH} 5$ with $81.28 \%$, $87.11 \%$ and $90.76 \%$ for every 50,20 and $10 \mathrm{mg} / \mathrm{l}$ fitted with an essential convergence of zink heavy metals individually. For 1:5 of polystyrene-silver NCs, it was evacuated zink heavy metals at $\mathrm{pH} 5$ with $82.35 \%, 87.52 \%$, and $91.39 \%$, for each essential centralization of 50, 20 and $10 \mathrm{mg} / \mathrm{l}$.

The end of zink heavy metals by polystyrene-silver NCs was most likely in light of the presence of $\mathrm{OH}$ - and $\mathrm{H}+$ factor. In less worth $\mathrm{pH}$, the being of $\mathrm{H}+$ rivaled $\mathrm{M}+$ particles through the exchange spots of particles, where $\mathrm{M}+$ showed as mass spectroscopy. thus, extra settled metal particles take-up brings about the higher discharging of $\mathrm{H}+$, exhibited that an ascent grouping of zink heavy metals would be discharging rise H+. Presented to Al-Asheh et al (1997), protonation of the adsorbent surface (silver surface right now) rise the extensive cacophony of metal particles inside the arrangement of the heavy metal at slice $\mathrm{pH}$, prompting decline the metal adsorption capacity at a run [11].

At greatest $\mathrm{pH}$ rates, the equipoise proportion of elimination competences of zink heavy minerals was spotted because of deprotonation. The minimal contest between the cations of the metal andproton, at the turn out of OH-. So, the reduction in the positive surface charge of polystyrene-silver NCs outcomes in the depress electrostatic repulsion among the metals ions of the zink heavy metals and the surface of polystyrene-silver NCs. The forming of the tractable hydroxyl congregation was also clearly proposed where additional alkali of the solution produce tractable hydroxyl gleaner to the solution of the particular [12].

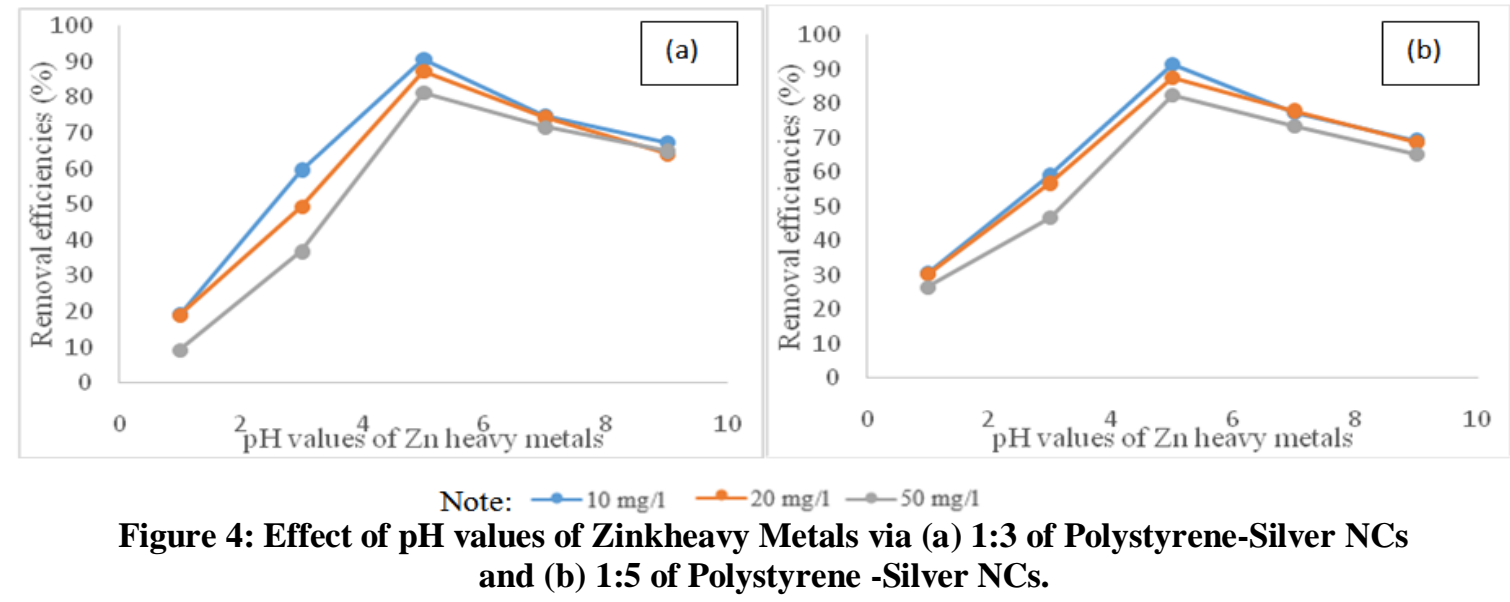

The contact time effect was clearly shown in Figure 5 (a) and (b). It shows that at $10 \mathrm{mg} / \mathrm{l}$ convergence of zink heavy metals, it demonstrated a steady increment in evacuation abilities, starting at 10 minutes to reach the most extreme expulsion efficiencies. At almost $91 \%$ expelled by 1:3 and 1:5 of polystyrene-silver NCs at 50 minutes, which was signified as the most elevated evacuation rate. The practically consistent pace of expulsion following 50 minutes was additionally seen until it arrives at 70 minutes. Similar qualities appeared at $20 \mathrm{mg} / \mathrm{l}$ and $50 \mathrm{mg} / \mathrm{l}$, yet have the most extreme evacuation rate at almost $87 \%$ and $82 \%$ individually. 
Figure 5 (b) shows a similar diagram shape like Figure 5 (a) where the zink metal ions begin to expel step by step at 10 minutes until they arrive at the pinnacle limit of evacuation efficiencies. It offers that about $92 \%$ of zink heavy metals expelled by 1:5 of polystyrene-silver NCs at 50 minutes, at that point it remains at nearly harmony province of zink particle evacuation until they arrive at 70 minutes of contact time. This is because that the impact of contact time relies upon the underlying centralization of heavy metals. If increasingly heavy metal was available, there will be marginally hard to evacuate because of similar properties of polystyrene-silver NCs arranged, depend upon its coupling locales and ions trade.The harmony state was accomplished for a similar fixation because of reliable mass exchange solid restricting locales of polystyrene-silver NCs towards zink ions.
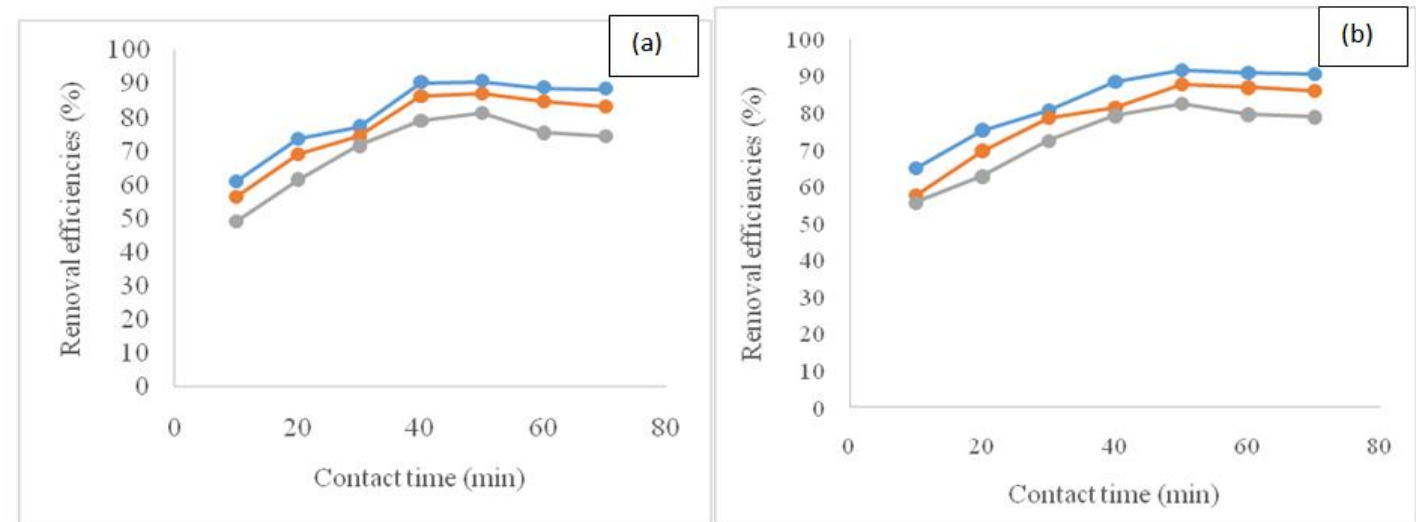

Note:

$\rightarrow 10 \mathrm{mg} / 1 \rightarrow 20 \mathrm{mg} / 1 \rightarrow 50 \mathrm{mg} / 1$

Figure 5: The Effect of Contact Time of Zinkheavy Metals via (a) 1:3 of Polystyrene-Silver NCs and (b) 1:5 of Polystyrene-Silver NCs.

\section{CONCLUSIONS}

The outcomes fundamentally demonstrate the evacuation of zink heavy metals at pH estimations of 5 about $91 \%$ at every centralization of arranged zink engineered wastewater $(10,20$ and $50 \mathrm{mg} / \mathrm{l})$ while the contact time of zink heavy metals expulsion, with specific $\mathrm{pH}$ estimations of five (5) arrived at the most extreme at fifty (50) minutes at almost $91 \%$. The outcomes effectively indicated that polystyrene-silver NCs have great restricting locales properties, which permits the trading of ions with the zink ions. The dynamic mass exchange among silver NPs and zink heavy metals because of solid restricting locales of silver caused huge sum expulsion of zink heavy metals, while polystyrene goes about as the casing specialist between the authoritative of silver NPs and zink. These test results would be extremely valuable in growing new advantages and research, particularly in nano technology applications in heavy metals expulsion ions for modern buildup wastewater or reusable household waste water through nanoparticle application.

\section{ACKNOWLEDGEMENT}

The authors are sincerely thankful to Ministry of Higher Education and the grant FRGS/1/2019/STG07/UTHM/02/5 (FRGS K171)

\section{REFERENCES}

1. E. Rosenberg, “'Heavy Metals in Water: Presence, Removal and Safety, '” Johnson Matthey Technol. Rev., vol. 59, no. 4, pp. 293-297, 2015. 
2. D. E. Rusyniak, A. Arroyo, J. Acciani, B. Froberg, L. Kao, and B. Furbee, "Heavy metal poisoning: management of intoxication and antidotes., " EXS, vol. 100, pp. 365-396, 2010.

3. P. K. Gautam, R. K. Gautam, S. Banerjee, M. C. Chattopadhyaya, and J. D. Pandey, "Heavy metals in the environment: Fate, transport, toxicity and remediation technologies," Heavy Met. Sources, Toxic. Remediat. Tech., no. March 2017, pp. 101-130, 2016.

4. S. Hanchang, "Industrial Wastewater- Types, Amounts and Effects," Point Sources Pollut. Local Eff. their Control, vol. I, pp. 191-203, 2009.

5. S. Babel and T. A. Kurniawan, "Low-cost adsorbents for heavy metals uptake from contaminated water: A review,” J. Hazard. Mater., vol. 97, no. 1-3, pp. 219-243, 2003.

6. D. S. Malik, C. K. Jain, and A. K. Yadav, "Removal of heavy metals from emerging cellulosic low-cost adsorbents: a review," Appl. Water Sci., vol. 7, no. 5, pp. 2113-2136, 2017.

7. R. Kumar and J. Chawla, “Removal of Cadmium Ion from Water/Wastewater by Nano-metal Oxides: A Review,” Water Qual. Expo. Heal., vol. 5, no. 4, pp. 215-226, 2014.

8. X. Du and R. Jin, “Atomically Precise Metal Nanoclusters for Catalysis,” ACS Nano, vol. 13, no. 7, pp. 7383-7387, 2019.

9. H. Wu, G. Wu, Y. Ren, X. Li, and L. Wang, "Multishelled Metal Oxide Hollow Spheres: Easy Synthesis and Formation Mechanism,” Chem. - A Eur. J., vol. 22, no. 26, pp. 8864-8871, 2016.

10. J. A. Yabagi, M. I. Kimpa, M. N. Muhammad, K. I. Uthaman, E. Zaidi, and M. A. Agam, "Structural transformation of polystyrene nanosphere produce positive and negative resists by controlled laser exposure,” Adv. Sci. Lett., vol. 23, no. 7, pp. 6613-6617, Jul. 2017.

11. Z. R. Jia, Z. G. Gao, D. Lan, Y. H. Cheng, G. L. Wu, and H. J. Wu, "Effects of filler loading and surface modification on electrical and thermal properties of epoxy/montmorillonite composite, " Chinese Phys. B, vol. 27, no. 11, 2018.

12. M. Q. Hamzah, S. O. Mezan, A. N. Tuama, A. H. Jabbar, and M. A. Agam, "Study and Characterization of Polystyrene/Titanium Dioxide Nanocomposites (PS/TiO2 NCs) for Photocatalytic Degradation Application: a Review, ”Int. J. Eng. Technol., 2018, doi: 10.14419/ijet.v7i4.30.28172.

13. M. Q. Hamzah, A. H. Jabbar, S. O. Mezan, A. N. Tuama, and M. A. Agam, "Fabrications of PS/TiO2 nanocomposite for solar cells applications," Nanosci. Nanotechnol. NANO-SciTech, vol. 2151, no. August, p. 020011, 2019.

14. S. O. Mezan et al., "Synthesis, characterization, and properties of polystyrene/SiO2 nanocomposite via sol-gel process," in AIP Conference Proceedings, 2019, vol. 2151, doi: 10.1063/1.5124664.

15. H. Jabbar, S. O. Mezan, A. N. Tuama, M. Q. Hamzah, A. S. B. Ameruddin, and M. A. Agam, "Enhanced bioactivity of polystyrene-silver nanocomposite (PS/Ag NCs)-an antimicrobial study, " in

16. S. Suresh, "Semiconductor Nanomaterials, Methods and Applications: A Review," Nanosci. Nanotechnol., vol. 3, no. 3, pp. 62-74, 2013.

17. C. Loos et al., "Functionalized polystyrene nanoparticles as a platform for studying bio-nano interactions," Beilstein J. Nanotechnol., vol. 5, no. 1, pp. 2403-2412, 2014.

18. Rafiq et al., "Synthesis and Microwave Absorption Properties of Doped Expanded Polystyrene with Silver Nanoparticles, ”J. Sci. Technol., vol. 9, no. 3, pp. 33-40, 2017.

19. J. Liu, H. Liang, Y. Zhang, G. Wu, and H. Wu, "Facile synthesis of ellipsoid-like MgCo2O4/Co3O4 composites for strong 
wideband microwave absorption application," Compos. Part B Eng., vol. 176, no. July, p. 107240, 2019.

20. Z. Jia, K. Lin, G. Wu, H. Xing, and H. Wu, “Recent progresses of high-temperature microwave-absorbing materials,” Nano, vol. 13, no. 6, pp. 1-13, 2018.

21. D. Lan et al., "Synthesis, characterization and microwave transparent properties of Mn 3 O 4 microspheres," J. Mater. Sci. Mater. Electron., vol. 30, no. 9, pp. 8771-8776, 2019.

22. P. Chandran, A. Ghosh, and S. Ramaprabhu, "High-performance Platinum-free oxygen reduction reaction and hydrogen oxidation reaction catalyst in polymer electrolyte membrane fuel cell," Sci. Rep., vol. 8, no. 1, pp. 1-11, 2018.

23. M. Mohamed, "Influence of nano materials on flexural behavior and compressive strength of concrete," HBRC J., vol. 12, no. 2, pp. 212-225, 2016.

24. H. Tang, S. Wang, M. Pan, and R. Yuan, "Porosity-graded micro-porous layers for polymer electrolyte membrane fuel cells," J. Power Sources, vol. 166, no. 1, pp. 41-46, 2007.

25. M. Qin et al., "Synthesis of Single-component Metal Oxides with Controllable Multi-shelled Structure and their Morphologyrelated Applications, ” Chem. Rec., pp. 1-19, 2019.

26. S. K. Shukla, Polymeric Materials for Clean Water. 2019.

27. B. Pan, B. Pan, W. Zhang, L. Lv, Q. Zhang, and S. Zheng, "Development of polymeric and polymer-based hybrid adsorbents for pollutants removal from waters, ” Chem. Eng. J., vol. 151, no. 1-3, pp. 19-29, 2009.

28. Y. Ye et al., "Efficient removal of Cr(III)-organic complexes from water using UV/Fe(III) system: Negligible Cr(VI) accumulation and mechanism," Water Res., vol. 126, pp. 172-178, 2017.

29. M. M. Nmaya et al., "Biosorption of heavy metals by scenedesmus sp. isolated from the temporary waters of endau Rompin, Johor, Malaysia," J. Teknol., vol. 77, no. 24, pp. 35-38, 2015.

30. C. Zhang, J. W. Chung, and R. D. Priestley, “Dialysis nanoprecipitation of polystyrene nanoparticles,” Macromol. Rapid Commun., vol. 33, no. 20, pp. 1798-1803, 2012.

31. L. Christensen, S. Vivekanandhan, M. Misra, and A. K. Mohanty, "Biosynthesis of silver nanoparticles using Murraya koenigii (curry leaf): An investigation on the effect of broth concentration in reduction mechanism and particle size," Adv. Mater. Lett., vol. 2, no. 6, pp. 429-434, 2011.

32. T. Roorkee, "Adsorption of Heavy Metal ( Cu2 +, Ni2 + and Zn2 + ) from Synthetic Waste Water by Tea Waste Adsorbent Adsorption of Heavy Metal ( Cu 2 +, Ni 2 + and Zn 2 +) from Synthetic Waste Water by..., " no. August, 2015.

33. H. T. John Ali, A. A. Jaber, S. Farhan, A. J. Fraih, and M. Q. Hamzah, "Study the Absorption and Attenuation Coefficient to a model of Spinel Ferrite (CoFe2O4) to absorb a spectrum from (X-Band) of the Microwaves before and after irradiate it with fast neutrons, " in Journal of Physics: Conference Series, 2019, vol. 1279, no. 1, doi: 10.1088/1742-6596/1279/1/012061.

34. M. H. Rady et al., "Effect of hot extrusion parameters on microhardness and microstructure in direct recycling of aluminium chips," Materwiss. Werksttech., 2019, doi: 10.1002/mawe.201800214.

35. R. A. Ismail, N. J. Almashhadani, and R. H. Sadik, "Preparation and properties of polystyrene incorporated with gold and silver nanoparticles for optoelectronic applications, "Appl. Nanosci., vol. 7, no. 3-4, pp. 109-116, 2017.

36. M. A. Agam1, N. N. Awal, S. A. Hassan, J. A. Yabagi, M. Q. Hamzah, A Talib, "Energy Band Gap Investigation Of Polystyrene Copper Oxide Nanocomposites Bombarded With Laser,” J. Adv. Res. Fluid Mech. Therm. Sci., Vol. 66, No.

2, Pp. 125-135, 2020. 